\title{
Addressing the Challenges of a Nuclear Phase-Out with Energy Synergies on Business Parks ${ }^{\dagger}$
}

\author{
Joannes Laveyne ${ }^{1, *}$, Jens Baetens ${ }^{1}$, Greet Van Eetvelde ${ }^{2}$ and Lieven Vandevelde ${ }^{1}$ \\ 1 Electrical Energy Laboratory (EELAB), Department of Electromechanical, Systems and Metal Engineering, \\ Ghent University, Tech Lane Ghent Science Park-Campus Ardoyen, 9052 Ghent, Belgium; \\ j.baetens@ugent.be (J.B.); lieven.vandevelde@ugent.be (L.V.) \\ 2 Energy \& Cluster Management (ECM), Department of Electromechanical, Systems and Metal Engineering, \\ Ghent University, Tech Lane Ghent Science Park-Campus Ardoyen, 9052 Ghent, Belgium; \\ greet.vaneetvelde@ugent.be \\ * Correspondence: joannes.laveyne@ugent.be \\ † Presented at the First World Energies Forum, 14 September-5 October 2020; Available online: \\ https://wef.sciforum.net/.
}

Published: 12 September 2020

\begin{abstract}
Similar to many other Western countries, Belgium has committed to internationally set climate goals, such as the reduction in primary energy consumption and the increase in the share of renewable energy production in the total energy mix. Additionally, Belgium has decided to phase out its nuclear energy production, the nation's largest source of low carbon electricity. In this paper, the role of Belgian business parks and industrial clusters in contributing to the climate goals is investigated, based on the experiences of the authors on several business parks and industrial clusters. The concepts of cogeneration, advanced thermal grids, and local energy communities are discussed and applied on pilot clusters. Their effectiveness towards achieving the climate goals is evaluated, and finally, some policy recommendations are proposed. The results are based on the Belgian situation but are valid for other countries facing similar challenges.
\end{abstract}

Keywords: energy transition; business parks; industrial clusters; heat exchange; industrial symbiosis; energy policy

\section{Introduction}

Similar to many Western countries, Belgium has committed itself to achieve internationally coordinated climate goals as set by the Paris Agreement on climate change and access to clean energy for all. Specifically, the primary energy consumption of 49.1 Mtoe measured in the year 2017 should be reduced to 43.7 Mtoe by 2030, while at the same time, the share of renewable energy in the gross final energy consumption should increase from $9.1 \%$ to $18.3 \%$ [1,2]. Recently, the European Commission has asked Belgium to increase the latter to $25 \%$ to be in line with the general EU level ambitions on clean energy [3,4].

The share of renewable energy production is growing at a steady pace, mainly fueled by large offshore wind projects and a widespread adoption of rooftop solar installations. Looking at installed capacity, wind energy has increased from $820 \mathrm{MW}$ in 2010 to $6.1 \mathrm{GW}$ in 2019, with solar increasing from $400 \mathrm{MW}$ to more than $6.2 \mathrm{GW}$ in the same time span. Meanwhile, the share of conventional thermal generation (gas-fired power plants) and nuclear power remained more or less steady at 7 GW and $6 \mathrm{GW}$, respectively $[5,6]$. Figure 1 shows the relative share of each generation source in the total installed generation capacity in Belgium as of 2020, with Figure 2 showing the share in the total electricity generation. 
$\square$ Fossil fuel $\square$ Nuclear $\square$ Hydro $\square$ Wind $\square$ Solar $\square$ Biomass $\square$ Pumped Hydro $\square$ Waste

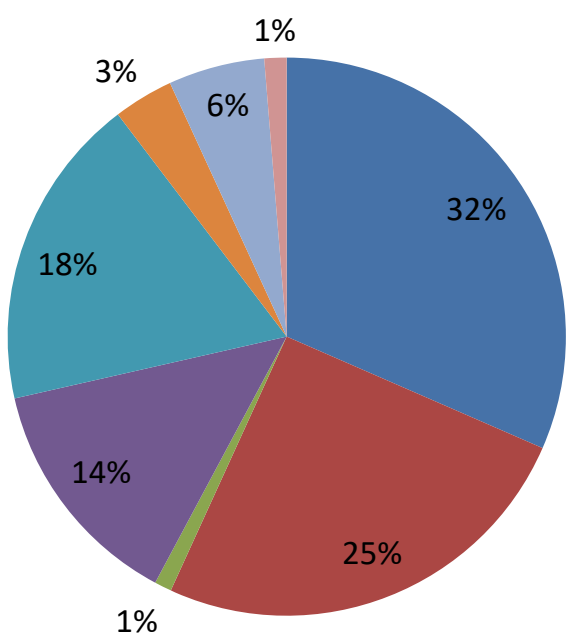

Figure 1. Relative share of installed electrical production capacity in Belgium, by source.

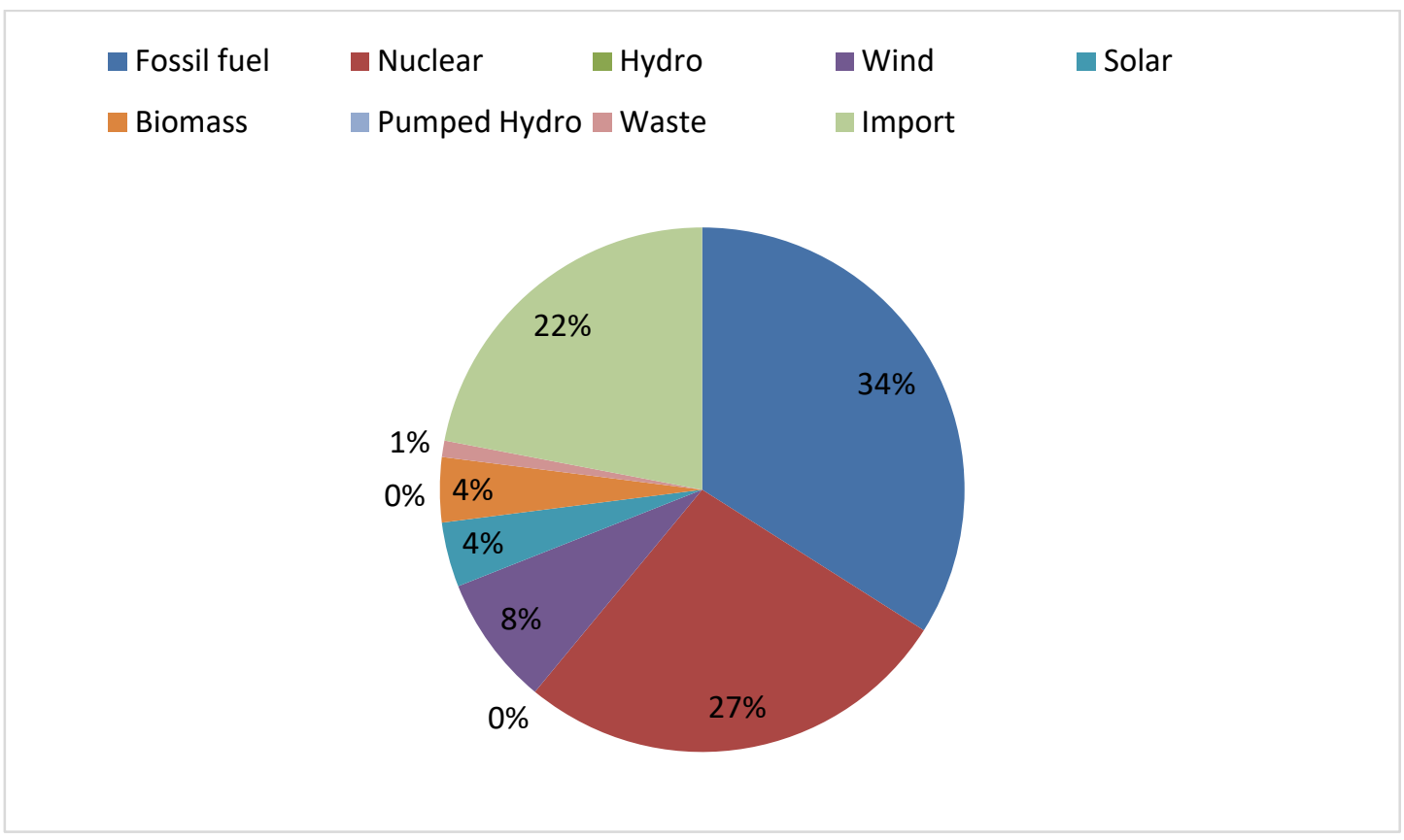

Figure 2. Relative share yearly electrical energy production in Belgium, by source.

Belgium has endorsed a nuclear phase-out policy that entails closing all of its six reactors in two nuclear power plants (NPP) by the end of 2025 [7]. This policy, accepted into law in 2003, has been the subject of many political debates and has been revised on several occasions. The 2025 deadline is still standing, however, and the operator of the Belgian NPPs has indicated it sees no economic justification in keeping all but two reactors online after 2025 [8].

The nuclear phase-out combined with the stringent goals on lowering primary energy use impose a kind of conundrum on Belgian energy policy. It is clear that to achieve significant primary energy reductions, interventions on both supply and demand side must be undertaken.

In this paper, the role Belgian business parks and industrial clusters can play in the energy transition is explored based on the experiences of the authors in three related projects. First, in Section 2 , the Belgian energy landscape is analyzed, describing both the current supply and demand side and expected evolutions. In Section 3, a few pilot cases and the innovations currently being explored are presented. The pros and cons of these are discussed in Section 4. Finally, Section 5 concludes with 
some policy recommendations to ensure industrial sectors can optimally contribute to the energy transition.

\section{The Belgian Energy Landscape and the Role of Industrial Clusters and Business Parks}

The Belgian energy production landscape is dominated by large and historical thermal assets, with 7.3 GW of gas-fired plants, mainly closed cycle gas turbines (CCGT) and some open cycle gas turbines (OCGT) and $6 \mathrm{GW}$ of NPPs. There is $1.3 \mathrm{GW}$ of pumped storage provided by the Coo reservoirs. The remaining $8.6 \mathrm{GW}$ is provided by renewables, mainly solar and (offshore) wind energy [5].

The Belgian electricity consumption totals around 81 TWh per year, 69 TWh is generally produced domestically, and the remainder is imported from other countries. Looking at domestic energy production, the numbers are somewhat different than one would expect from the capacity of the installed assets. Nuclear power delivered around $34 \%$ of the total energy production. Gas-fired plants delivered $21.3 \%$ of the total [9]. Due to technical or economic reasons, some of the gas-fired plants are not fully in the market anymore or only kept online as peaking units. Renewable energy climbed to $17 \%$ of total energy production, with imports making up the rest [10].

Figure 3 shows the relative share of each industrial sector in the Belgian final energy consumption. With around $47 \%$, industry has by far the largest share in the final domestic electricity consumption. The share of commercial services such as retail, offices, and public services is around $26 \%$. Households consume up to $21 \%$. The remainder is equally split between residual consumer segments such as agriculture or transport.

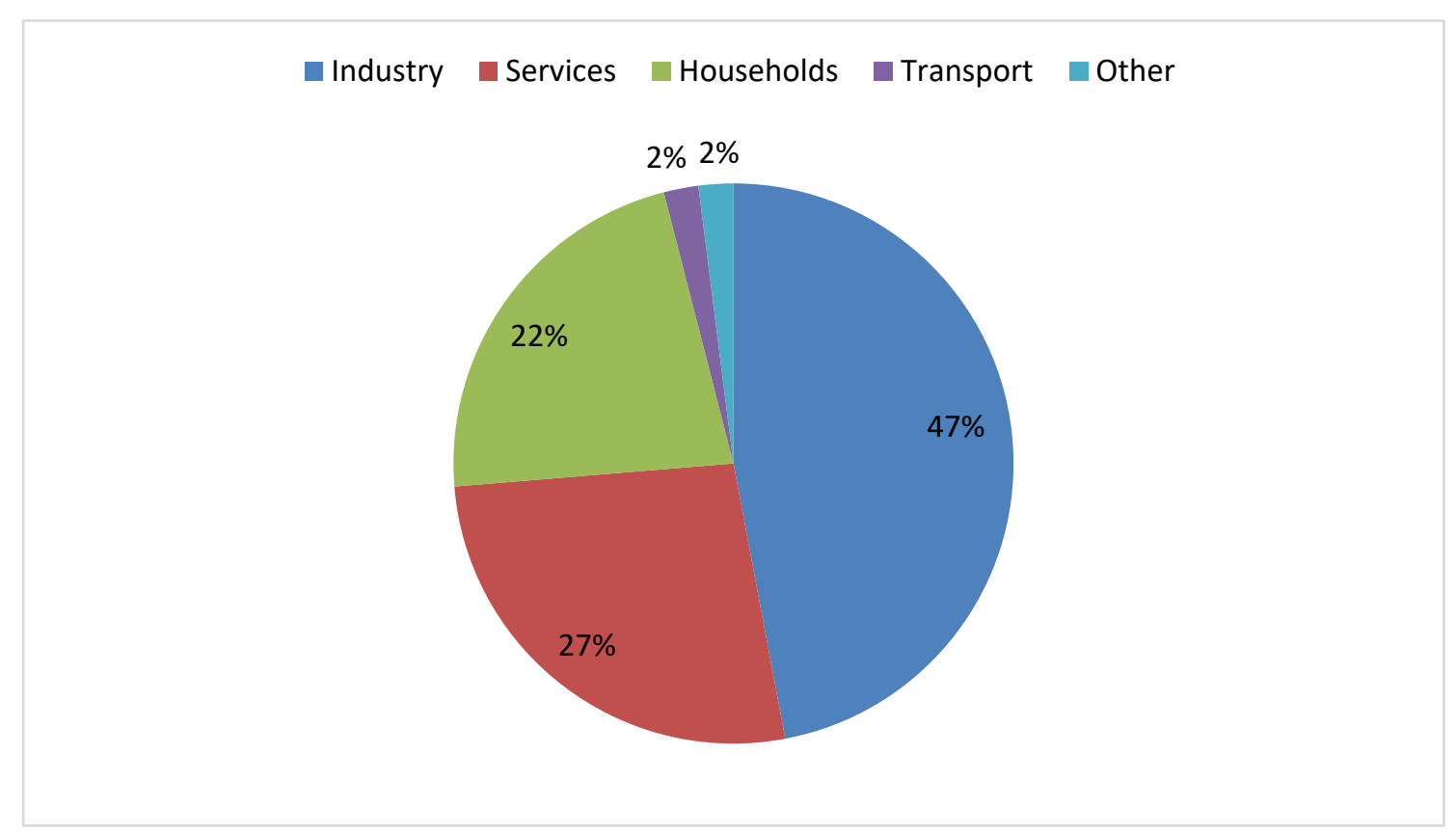

Figure 3. Relative share final electricity consumption in Belgium, by sector.

Further breaking down the industrial electricity use, it shows that the chemical and petrochemical sectors are the largest industrial end users of electricity, with a share of $38 \%$ in the industrial and $18 \%$ of the total domestic electricity consumption. This is mainly attributed to a large concentration of chemical and petrochemical clusters built up around the ports of Antwerp and Ghent. Foodstuffs and ironworks make up second and third place with $16 \%$ and $11 \%$ of the total industrial electricity use, respectively.

These figures show that electricity use in Belgium is mainly concentrated in the large industrial clusters and in the many scattered business parks, the latter often combining light industrial activities with services such as retail or office spaces [11]. 


\section{Experiences with Pilot Sites in Belgium}

This section contains the experiences of the authors on several Belgian business parks analyzed and guided during multiple research and demonstration projects.

The EU Interreg 2 Seas project Business Integrated Sustainable Energy Packages (BISEPS) project inventoried eight different business parks spread over four countries, with five parks located in Belgium. The overall goal of BISEPS is to increase the adoption of midscale sustainable energy technologies (heat exchange, wind turbines, biomass combustion, combined heat and power, smart grids, or large-scale solar) in business clusters resulting in less carbon emissions and a greener and competitive 2 Seas region. The method of operation is the reorganization and clustering of both demand and supply side within the current technological constraints, while identifying legal and economic barriers preventing the rollout of these concepts beyond pilot sites [12].

The VLAIO Flux50 project Roll-out of Local Energy Communities (ROLECS) project encompasses 10 additional pilot sites, with six business parks and two sites combining industrial activities with commercial and civil services such as schools and habitation. The project aims at analyzing, testing, and implementing local energy communities on these sites, establishing relevant technologies, organizational approaches, and implementation strategies, while also identifying economic and legal barriers. The concept of these energy communities shows great potential in encouraging new business opportunities in a sustainable way, lowering primary energy consumption compared to the usual business development strategies [13].

Additionally, the recently started EU Interreg 2 Seas project Local Energy Communities for the 2 Seas Region (LECSEA) aims at developing eight lighthouse projects where primary energy reduction and renewable energy production will be boosted by implementing the synergy opportunities in the BISEPS project within an energy community framework. Specific emphasis is put on creating so-called energy hubs, sites where multiple energy carriers are available (e.g., existing heat network, high pressure natural gas pipeline, and access to the Belgian hydrogen pipeline network), exploring the technical potential of using these different carriers in a flexible and interchangeable way [14].

The next subsections describe technological concepts that the authors feel could be a common solution for most Belgian business parks and industrial clusters in order to lower primary energy consumption. Economic and regulatory barriers preventing a more general adoption of these technologies are presented and are followed up by a discussion in Section 4 .

\subsection{Heat Exchange}

Most Belgian business parks and industrial clusters are characterized by a high demand for both electrical and thermal energy, but also by a relative high share of available waste heat $[15,16]$. Both heat and electricity are often produced by each company individually, especially on business parks [17]. By exploiting synergies between demand and supply profiles of all companies on the same business park or industrial cluster, a reduction in primary energy consumption and an increase in profitability of (renewable) energy producing investments could be achieved.

Heat exchange is possible with so-called heat exchange networks: a closed loop system where heat in the form of steam or (super)heated water is circulated from one or more sources to one or more consumers. Typically, these networks are categorized in generations, where networks of an older generation generally work on higher temperatures and incur more losses per unit of distance, while newer networks tend to work on lower temperatures and operate more efficiently [18]. Most heat exchange networks in Belgium are third generation, with temperatures not exceeding $100{ }^{\circ} \mathrm{C}$ and heat often produced by a relatively large fossil-fired power plant. However, some fourthgeneration networks are being deployed, with temperatures of around $65^{\circ} \mathrm{C}$ and mainly powered by waste heat.

One thing first to fourth generation heat networks have in common is that they distribute heat from one central supplier to one or more consumers. In this light, they have some resemblance to the way the electrical grid historically was designed. In order to fully exploit synergies between 
individual companies and their specific processes, a multi-source to multi-consumer topology is required, essentially transforming them to heat sharing networks instead of purely distribution [19].

Fifth-generation heat networks are characterized by the possibility of heat sharing. In networks of these types, temperatures are lower than $65{ }^{\circ} \mathrm{C}$, vastly reducing heat loss and simplifying connection for space heating applications. Consumers requiring higher temperatures can employ electric heat pumps to raise the temperature or use the hot water as preheated input for their boiler system. Waste heat then returns into the grid, closing the loop. Additionally, heat pumps can be used in reverse to provide cooling, with the waste heat being injected into the grid.

Fifth generation heat networks are currently in demonstration phase; none have been deployed in Belgium yet. One of the main obstacles is non-existent regulation. The heat market currently does not fall under any regulatory oversight, which does simplify the process of designing and implementing a heat network. This also implies that third party access (TPA) is not required. In most cases the owner of the network is also the owner of the heat production installation, leading to a form of local mini-monopolies, exposing the consumer to unregulated tariffs. From a conceptual standpoint, this does not fit the concept of fifth generation networks, where each producer can also be a consumer, taking the so-called prosumer role, and as such, heat can come from many parties not necessarily having a stake in the network.

\subsection{Cogeneration}

Combined generation or cogeneration is the simultaneous generation of two types of energy carrier, predominantly heat and electricity through a combined heat and power (CHP) installation. Cogeneration is an already widely established technology, ranging from micro-CHPs of only a few kilowatts of power to power-plant-scale installation of hundreds of megawatts. In Belgium, small CHPs are commonly used in agricultural applications, with bigger installations encountered in industrial clusters. The common fuel source is natural gas $[20,21]$.

The traditional deployment strategy for cogeneration is to size the installation according to the thermal demand of one or more consumers, maximizing the amount of running hours through a static calculation. In practice, this limits the deployment of cogeneration mostly to industrial use cases with a thermal baseload demand. In typical business parks, the demand for heat is mostly limited, in small parks sometimes even consisting only of space heating needs.

It can, however, be shown that a reduced cogeneration installation primarily sized on electrical demand can still have positive impacts on the reduction in total primary energy consumption, possibly even outperforming conventionally sized CHPs because of the better integration into the electrical grid [22]. Indeed, with lower thermal constraints, the power plant can more easily perform electrical load-following or provide balancing services [23].

Cogeneration can also be coupled to absorption cooling systems, producing electricity, heat, and cooling. This concept is known as trigeneration.

\subsection{Local Energy Communities}

Local energy communities (LECs) are a broad term encompassing several concepts of energy consumers, producers and prosumers, who both produce and consume energy, working together to exchange energy with each other or with the grid in a coordinated way. LECs find their origin in the Clean energy for all Europeans package, leading to their inclusion into directive (EU) 2019/944 of the European Parliament and of the Council of 5 June 2019 on common rules for the internal market for electricity, commonly called the Energy Market Design (EMD) [24], and the recast directive (EU) 2018/2001 of the European Parliament and of the Council of 11 December 2018 on the promotion of the use of energy from renewable sources, commonly called the Renewable Energy Directive II (REDII) [25]. Both directives must be implemented in national law by the European member states by the end of 2020 [26].

Concerning energy communities, two concepts within the directives are of importance. The first is the citizen energy community (CEC), which is defined as a voluntary and open cooperation that may engage in activities such as energy generation, distribution, consumption, aggregation, 
aggregation, services, and electric vehicle (EV) charging, for the purpose of providing environmental, economic or social benefits to members of the community or their shareholders. These shareholders must be natural persons, local authorities, or small companies.

A renewable energy community (REC) is likewise defined as a voluntary and open cooperation, which may engage in all the same activities except EV charging but requires each shareholder to be located in the physical proximity of the activities taking place. The energy exchanged must originate from renewable sources, and the shareholding is open to small and medium enterprises (SMEs). Table 1 gives an overview of the different rights an obligation of each type of LEC.

Table 1. Overview of rights and obligations of a citizen energy community (CEC) and a renewable energy community (REC) on several energy aspects.

\begin{tabular}{ccc}
\hline \multicolumn{1}{c}{ Aspect } & Citizen Energy Community & Renewable Energy Community \\
\hline $\begin{array}{c}\text { Energy production } \\
\text { trading, storage }\end{array}$ & $\begin{array}{c}\text { From renewable sources or } \\
\text { qualitative CHP }\end{array}$ & From renewable sources \\
\hline Sale of energy & Allowed within community & Allowed within community \\
\hline Grid services & Flexibility, aggregation, EV charging \\
Shareholders & $\begin{array}{c}\text { Natural persons, small enterprises, } \\
\text { local government }\end{array}$ & Allowed within the community \\
\hline Locality criterium & No & Flexibility, aggregation \\
\hline
\end{tabular}

Table legend: CHP: Combined Heat and Power, EV: Electric Vehicle.

The benefit of these community concepts is the possibility of energy exchange between members without having to meet the obligations of an energy supplier, which includes, e.g., portfolio balancing and being able to exchange and settle energy even if members have different energy suppliers. This so-called peer-to-peer (P2P) trading enables the trading of energy surpluses or shortages within the community, also opening possibilities of a member investing in renewable energy production on sites of other members, e.g., because the site of the former has limited potential for renewable energy production [27].

In the ROLECS project, the authors have investigated the implementation of a local energy community from a technical, economic, and regulatory aspect on 10 different pilot sites, six of which were business parks.

Two regulatory issues arise from the directives, severely handicapping the application to business parks and industrial clusters. First is the exclusion of large enterprises from both community concepts. While most Belgian business parks consist of SMEs, industrial clusters contain large enterprises as well. It can be assumed that these companies generally have a large energy and climate footprint. The exclusion from the community effectively disables the possibility of smaller companies on the same business park or industrial cluster to exploit energy profile opportunities of the larger company, e.g., the surplus generated or shortage of consumed energy.

While RECs allow SMEs to partake in the shareholding and as such could be of use for most of the Belgian business parks, they are limited to the exchange of renewable energy, whereas CECs can also trade energy generated by qualitative CHP between members. As shown in Sections 3.1 and 3.2, gas-fired cogeneration is a viable and relatively easily implemented method of lowering primary energy use and associated emissions, and being able to exchange the energy without regulatory burdens would be another investment incentive. We therefore identify the exclusions of qualitative CHP from the REC concept as the second issue.

A third issue, displayed in Figure 4, is more inherent to the Belgian situation, namely the composition of the final energy price as paid by consumers. For an end-user connected to the low voltage grid, the energy component only compromises $29 \%$ of the total end price. VAT, taxes, and levies take up an additional $28 \%$, with the remaining $43 \%$ going towards grid tariffs $[28,29]$. The 
European directives only apply to the energy component, implying that every unit of economic benefit realized through an energy community will only count for one third in the final energy price.

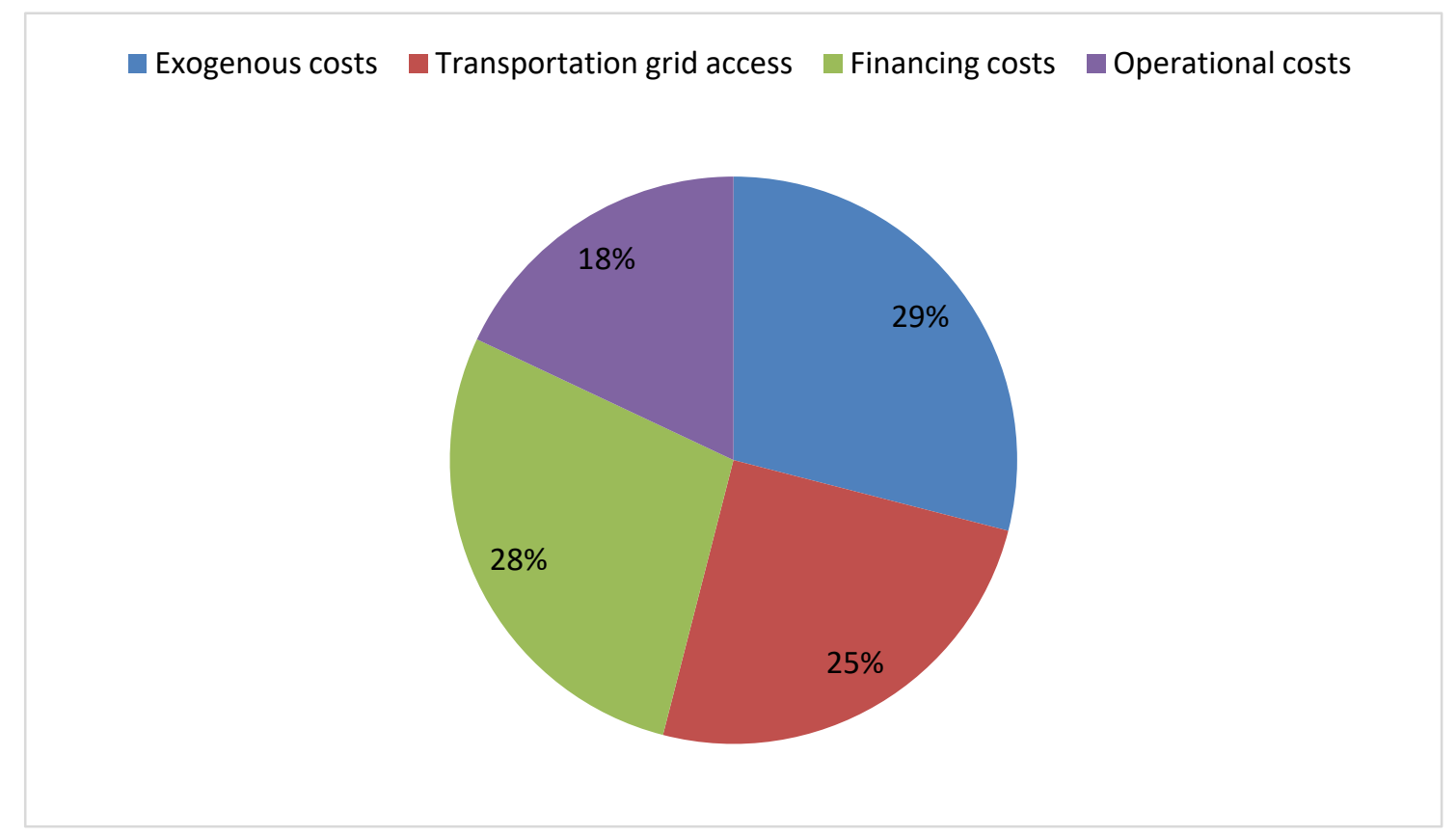

Figure 4. Relative share of different cost items in the Flemish distribution grid tariff.

The high share of grid tariffs is mainly due to the distribution grid tariff and its high share of socalled exogenous costs, or costs outside the control of the Distribution System Operator (DSO). Fiftyfour percent of these costs are incurred by the governmental policy of making the DSO carry the economic support of distributed renewable energy (DRES) installations and energy efficiency (EE) measures [30]. For comparison, the actual operational costs of the DSO, included in the endogenous costs, only takes up about $18 \%$ of the total grid tariff.

\section{Discussion}

In this section, we discuss some of the economic and regulatory issues that prevent the concepts presented in Section 3 of being rolled out more widely on Belgian business parks and industrial clusters.

One of the main issues with implementing innovative energy concepts is the twisted grid tariffing situation. As shown in Section 3.3, 43\% of the price the end consumer pays for electricity goes to grid tariffs, but the share of actual grid operational costs is very limited. The EMD and REDII directives only affect the $29 \%$ of the total price compromising the energy component, severely reducing the impact on the total cost.

Incentivizing innovative energy concepts through an exemption of grid tariffs is, however, not an option, both from a regulatory and societal point of view. Grid tariffs have an import function in the redistribution and maximization of welfare. By socializing the cost of grid connections, citizens are ensured affordable access to energy independent of their living are (e.g., a more rural province). Including the economic support for DRES and EE measures into the tariffs only increases this redistributory aspect. Giving customers the option to opt out on certain grid tariffs if they invest in innovative energy concepts thus runs the risk of creating the so-called Matthew effect, where the burden of the system ends up being paid by a decreasing base of customers without the economic or physical means for taking part in these concepts.

A more sensible solution is an overhaul of the tariffing structure, where the amount of exogenous costs are reduced or transferred to other fiscal instruments such as direct subsidies and taxes. This has the benefit of being a more transparent system, while also increasing the impact of the EMD and REDII directives on the final energy price. A drawback is that the resulting lower end 
energy cost might discourage investments in EE and increase unnecessary energy use. Some form of corrective measure must therefore be implemented as well, e.g., a so-called carbon tax. This will keep the incentive for EE high, while also incentivizing innovative energy concepts where EE cannot be raised, e.g., in industrial processes.

Another regulatory concern is the legislative void in which heat networks currently operate. While for all practical purposes this is generally conceived as positive, it also poses significant drawbacks on project initiation and connected consumer rights. The financial risk of initiating heat exchange operations now solely lies with the grid owner/investor. This stimulates the owner to charge grid tariffs to connected consumers that at least match their cost of capital. This is only possible if they are the sole supplier of heat, creating a monopoly. If other means of heat generation are available, generally through individual heat generation with natural gas, the option of a heat network is generally not considered.

If heat networks were a regulated market, with construction and operation delegated to cities, local governments, or DSOs, the construction of such networks could be incentivized more easily by the central government. It would also guarantee open access for consumers and competitive energy prices by allowing multiple heat suppliers. The Netherlands, in the light of the national "exit from gas", are pursuing such a strategy.

A third discussion point is the limitation of REC to renewable energy sources. As is shown in Section 3.2, qualitative cogeneration is a valid option to reduce primary energy use and final observed carbon emissions. Gas-fired cogeneration also has the benefit of improved integration into the electrical grid. Step-power response can be very fast, in contrast to most biomass fed power generators. Large-scale biomass power stations can also be difficult to provide truly sustainable feedstock for.

Smaller-sized cogeneration units also seem to be very suited for business parks, assuming heat and electricity can be distributed economically, especially when complemented with large installations of solar panels. These produce electricity primarily during the times of the year where heat demand is low.

\section{Conclusions}

This paper gave a brief overview of the current Belgian energy landscape and future trends and policies. It was shown how the commitment to reducing primary energy consumption, while holding on to a phase-out of nuclear power, up until now providing the nation's largest share of low carbon energy, poses a serious challenge. Some experiences and insights the authors gathered from multiple projects involving business parks and industrial clusters were shared, indicating how they can contribute to achieving the policy goals. We focused on three technologies, which can be easily and widely integrated on these sites: cogeneration, heat networks, and local energy communities. Some economic and regulatory obstacles preventing this widespread adoption were discussed, and some legislative changes proposed.

Primarily, the authors believe that a fundamental change in grid tariffing should be induced, raising the relative weight of the energy component and thus ensuring that the European EMD and REDII directives have a more pronounced impact. A carbon-based pricing could prove to be a more just measure. Additionally, regulating the heat energy market in a similar way as the electricity market could lead to a more widespread adoption of heat networks, valorizing industrial waste heat and increasing innovation. Finally, including qualitative cogeneration into local energy communities would be beneficial for adoption of these concepts into an industrial context.

While these results are primarily focused on the Belgian situation, they are relevant for other countries facing similar situations and conditions. Currently, the presented concepts are being deployed on several of the projects pilot sites, resulting in follow-up research on the effectives and efficacy of the proposed measures. 
Author Contributions: Conceptualization, J.L. and J.B.; Data curation, J.L.; software, J.L.; Funding acquisition, J.L., G.V.E. and L.V.; Methodology, J.L.; Project administration, L.V.; Writing-original draft, J.L.; writingreview and editing, J.L., J.B. G.V.E. and L.V.; visualisation, J.L. All authors have read and agreed to the published version of the manuscript.

Funding: This research was funded by the EU Intereg 2 Seas projects BISEPS “Business Integrated Sustainable Energy Packages" and LECSEA “Local Energy Communities for the 2 Seas region" and VLAIO Flux50 ICON HBC.2018.0527 ROLECS “Roll-out of Local Energy Communities”.

Acknowledgments: In this section you can acknowledge any support given which is not covered by the author contribution or funding sections. This may include administrative and technical support, or donations in kind (e.g., materials used for experiments).

Conflicts of Interest: The authors declare no conflict of interest.

\section{References}

1. European Commission. Summary of the Commission Assessment of the Draft National Energy and Climate Plan 2021-2030; European Commission: Brussels, Belgium, 2020.

2. FPS Economy. Energy - Key Data. Available online: https://economie.fgov.be/nl/publicaties/energy-keydata-maart-2020 (accessed on 29 May 2020).

3. VRT. Environment Minister Clashes with EU on Climate Goals. Available online: https://www.vrt.be/vrtnws/en/2019/12/12/environment-minister-clashes-with-eu-on-climate-goals/ (accessed on 29 May 2020).

4. European Commission. The European Green Deal; European Commission: Brussels, Belgium, 2020.

5. FEBEG. Statistieken Elektriciteit. Available online: https://www.febeg.be/statistieken-elektriciteit (accessed on 29 May 2020).

6. EnergyVille. Fact Check: The Belgian Energy Provision of Electricity in the Winter of 2018-2019. Available online: https://www.energyville.be/en/press/fact-check-belgian-energy-provision-electricity-winter-20182019 (accessed on 29 May 2020).

7. FOD Economie. Wet Houdende de Geleidelijke Uitstap Uit Kernenergie Voor Industriële Elektriciteitsproductie. Available online: http://www.ejustice.just.fgov.be/cgi_loi/change_lg.pl?language= nl\&la=N\&cn=2003013138\&table_name=wet (accessed on 29 May 2020).

8. Nieuwsblad. Electrabel Vraagt Wilmès Kernuitstap uit te Stellen. Available online: https://www.nieuwsblad.be/cnt/dmf20200416_04924174 (accessed on 21 May 2020).

9. Statbel. Energy Statistics by Economic Sector and by Energy Source. Available online: https://statbel.fgov.be/en/themes/energy/energy-statistics-economic-sector-and-energy-source (accessed on 29 May 2020).

10. Elia. Figures on Belgium's 2018 Energy Mix. 2020. Available online: https://www.elia.be/en/news/pressreleases/2019/01/20190118_press-release-elia-releases-its-figures-on-belgiums-2018-energy-mix (accessed on 29 May 2020).

11. Agentschap Innoveren \& Ondernemen. Data over Bedrijven en Bedrijventerreinen. Available online: https://www.vlaio.be/nl/andere-doelgroepen/lokale-besturen/lokaal-bedrijfshuisvestingsbeleid-enadvies/data-over-bedrijven (accessed on 29 May 2020).

12. BISEPS Project Website. Available online: http://www.biseps.eu/ (accessed on 29 May 2020).

13. ROLECS Project Website. Available online: https://rolecs.eu (accessed on 29 May 2020).

14. Interreg-LECSEA Project. Available online: https://www.interreg2seas.eu/nl/LECSEA (accessed on 29 May 2020).

15. Timmerman, J.; Deckmyn, C.; Vandevelde, L.; van Eetvelde, G. Low Carbonbusiness Parkmanual: A Guide for Developing and Managing Energy Efficient and Low Carbon Businesses and Business Parks; Ghent University: Ghent, Belgium, 2014; ISBN 9789082233001.

16. Timmerman, J.; Hennen, M.; Bardow, A.; Lodewijks, P.; Vandevelde, L.; Van Eetvelde, G. Towards low carbon business park energy systems: A holistic techno-economic optimisation model. Energy 2017, 125, 747-770.

17. Block, C.; Van Praet, B.; Windels, T.; Vermeulen, I.; Dangreau, G.; Overmeire, A.; D'Hooge, E.; Maes, T.; Van Eetvelde, G.; Vandecasteele, C. Toward a Carbon DioxideNeutral Industrial Park. J. Ind. Ecol. 2011, 15, 574-596. 
18. Lopes, J.P.; Hatziargyriou, N.; Mutale, J.; Djapic, P.; Jenkins, N. Integrating distributed generation into electric power systems: A review of drivers, challenges and opportunities. Electr. Power Syst. Res. 2007, 77, 1189-1203, doi:10.1016/j.epsr.2006.08.016.

19. Buffa, S.; Cozzini, M.; D'Antoni, M.; Baratieri, M.; Fedrizzi, R. 5th generation district heating and cooling systems: A review of existing cases in Europe. Renew. Sustain. Energy Rev. 2019, 104, 504-522, doi:10.1016/j.rser.2018.12.059.

20. Voorspools, K.; D'Haeseleer, W. The impact of the implementation of cogeneration in a given energetic context. IEEE Trans. Energy Convers. 2003, 18, 135-141, doi:10.1109/tec.2002.808332.

21. De Paepe, M.; Mertens, D. Combined heat and power in a liberalised energy market. Energy Convers. Manag. 2007, 48, 2542-2555, doi:10.1016/j.enconman.2007.03.019.

22. Carrero, M.M.; Sánchez, I.R.; De Paepe, W.; Parente, A.; Contino, F. Is There a Future for Small-Scale Cogeneration in Europe? Economic and Policy Analysis of the Internal Combustion Engine, Micro Gas Turbine and Micro Humid Air Turbine Cycles. Energies 2019, 12, 413, doi:10.3390/en12030413.

23. Voorspools, K.R.; D'Haeseleer, W.D. Reinventing hot water? Appl. Therm. Eng. 2006, 26, 1972-1981, doi:10.1016/j.applthermaleng.2006.01.012.

24. European Commission. Directive (EU) 2019/944 of the European Parliament and of the Council of 5 June 2019 on Common Rules for the Internal Market for Electricity and Amending Directive 2012/27/EU. Available online: https://eur-lex.europa.eu/legal-content/EN/TXT/?uri=CELEX\%3A32019L0944 (accessed on 29 May 2020).

25. European Commission. Directive (EU) 2018/2001 of the European Parliament and of the Council of 11 December 2018 on the Promotion of the Use of Energy from Renewable Sources. Available online: https://eur-lex.europa.eu/legal-content/EN/TXT/?uri=CELEX\%3A32018L2001 (accessed on 29 May 2020).

26. CEER. Regulatory Aspects of Self-Consumption and Energy Communities; Council of European Energy Regulators: Brussels, Belgium, 2019.

27. Sousa, T.; Soares, T.; Pinson, P.; Moret, F.; Baroche, T.; Sorin, E. Peer-to-peer and community-based markets: A comprehensive review. Renew. Sustain. Energy Rev. 2019, 104, 367-378, doi:10.1016/j.rser.2019.01.036.

28. Bollen, A.; Berckvens, D. Financiering van de energie-en klimaattransitie; SERV: Brussels, Belgium, 2019.

29. VREG. Rapport Met Betrekking Tot Het Toegelaten Inkomen van de Distributienetbeheerders in Vlaanderen uit hun Periodieke Distributienettarieven Voor 2020; VREG: Brussel, Belgium, 2019.

30. VREG. Tariefmethodologie Reguleringsperiode 2017-2020; VREG: Brussel, Belgium, 2018. 